\title{
TERROR Y BUROCRACIA: EL TEATRO DEL GRAND GUIGNOL DE PARÍS Y LA CENSURA
}

\section{TERROR AND BUREAUCRACY: THE THEATER OF THE GRAND GUIGNOL OF PARIS AND CENSORSHIP}

\author{
Alejandro Ocaña Fernández \\ (Universidad de Málaga, España) \\ a2ocana@gmail.com
}

Recibido: 30 de junio 2020 / Aceptado: 31 de julio 2020

\begin{abstract}
Resumen: El Grand Guignol de París fue una compañía teatral que se especializó en representar obras de teatro breve, siendo el género más recurrente el del terror, con obras plagadas de sadismo, crueldad y violencia exacerbada. Desde su mismo inicio, el Grand Guignol tuvo problemas con la censura, en forma de impedimentos para conceder las llamadas visas o autorizaciones que permitían la representación de los distintos espectáculos. Se examina en este artículo distintos casos de censura a que fue sometido el Grand Guignol, la forma en que fueron eludidos, el efecto que produjo en la marcha de la compañía y el modo en que dichos casos de censura sirvieron como reflejo del ambiente sociopolítico en el París de la época.
\end{abstract}

Palabras clave: Teatro; Francia; terror; censura, burocracia

\begin{abstract}
The Grand Guignol of Paris was a theater company specialized in representing short plays, the most recurring genre being that of terror, with works plagued by sadism, cruelty and exacerbated violence. From the very beginning, the Grand Guignol had problems with censorship, in the form of impediments to grant the so-called visas or authorizations that allowed the representation of the different shows. This article examines different cases of censorship to which the Grand Guignol was submitted, the way in which they were evaded, the effect it produced on the company's progress, and the way in which such censorship cases served as a reflection of the sociopolitical context in the Paris of the time.
\end{abstract}

Keywords: Theater; France; terror; censorship, bureaucracy 


\section{Introducción}

Le théâtre du Grand Guignol du Paris, o sencillamente el Grand Guignol, fue una compañía teatral que desarrolló su actividad entre 1897 y 1962.

Tenía su sede en una pequeña sala que, aunque ubicada en Pigalle, se encontraba muy cercana al barrio de Montmartre, participando de esta manera en el ambiente bohemio, alternativo, contestatario y rebelde que caracterizaba aquella zona de París situada a la sombra de la basílica del Sacré Coeur. La sala era una antigua capilla neogótica que, aunque desacralizada, conservaba su decoración religiosa. Esta decoración le otorgaba al local un cierto aire misterioso y lúgubre. [Fig. 1]

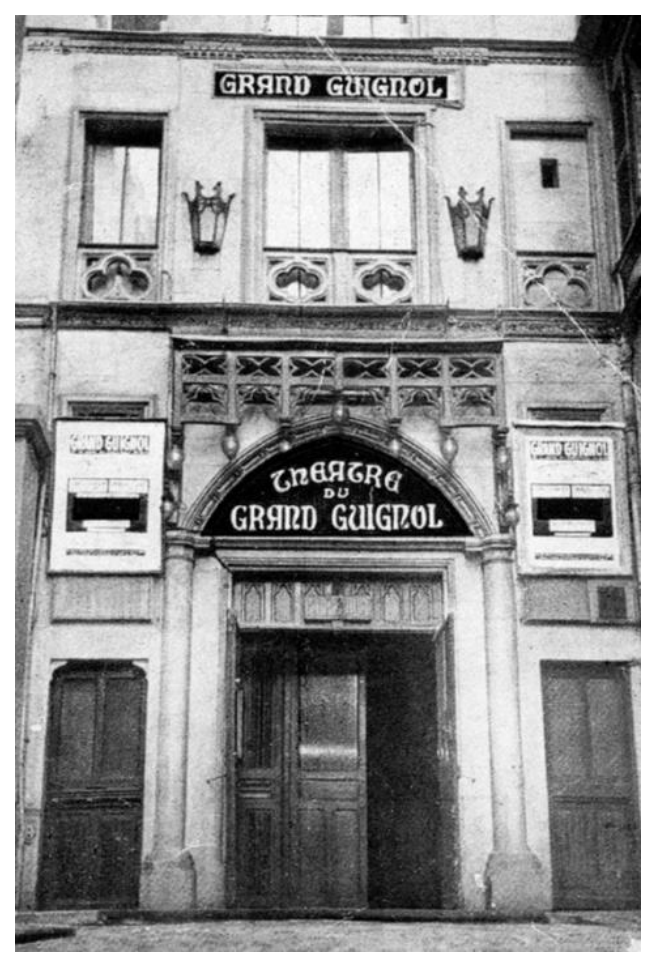

1.Fachada del Grand Guignol. Ca. 1950. Archivo del consorcio Time-Life.

Se especializó el Grand Guignol en subir a escena obras de teatro breve, de tal manera que los programas que componían sus sesiones estaban constituidos por entre tres y seis obras que combinaban distintos géneros: dramas, comedia, sainetes, vodeviles y números musicales. Pero el género que más caracterizó al Grand Guignol, y al que debe su fama, fue el del terror; pero no un terror cualquiera. Estas piezas no se limitaban a crear una atmósfera de tensión o a evocar cándidas fórmulas del pasado como pudieran ser, por ejemplo, las apariciones fantasmales. En la escena del Grand 
Guignol había crueldad y violencia exacerbada en forma de mutilaciones, decapitaciones, apuñalamientos, entre otros muchos actos de sadismo. Las obras en sí solían tener argumentos enormemente escabrosos y muy perturbadores (crímenes cometidos en el seno del ámbito familiar, comportamientos violentos de enfermos mentales, torturas perpetradas en lugares exóticos por agentes locales, etc.), pero más intimidante resultaba aun la puesta en escena, en donde no se escatimaba en trucajes escénicos y efectos especiales de todo tipo para crear ambientes siniestros $\mathrm{y}$, muy especialmente, para dar veracidad a los actos de violencia extrema que tenían lugar sobre el escenario.

Ni que decir tiene que desde su mismo inicio el Grand Guignol tuvo problemas con la censura. Se vio afectado, efectivamente, por muchos impedimentos para obtener las llamadas visas o autorizaciones que permitían la representación de sus espectáculos.

Es objeto de este estudio cómo el Grand Guignol se enfrentó al problema de la censura que, sobre todo en sus primeros años, fue especialmente severo, y cómo la compañía supo no solo sobreponerse a esos problemas sino también poder sacar partido de estos. Todo ello como reflejo del contexto sociopolítico y cultural que se vivía en una metrópolis sofisticada como era el París de la época.

\section{Antecedentes: el Théâtre Libre de André Antoine}

El fundador y director del Grand Guignol fue Óscar Méténier (1859 - 1913). Estudió con los Padres Jesuitas y al cumplir los 18 años se alistó en el $13^{\circ}$ Regimiento de Artillería. Una vez licenciado, se convirtió en secretario del comisionado de policía de París en el barrio de la Tour Saint-Jacques, cargo que ocuparía durante seis años y durante los cuales se dedicó igualmente a escribir novelas, obras teatrales y, sobre todo, relatos para revistas y periódicos de gran tirada como Gil Blas y Le Journal. Su experiencia en la policía le había convertido en un gran conocedor de los bajos fondos parisienses y de los barrios marginales, en los modos de proceder del hampa y en el lenguaje propio de los delincuentes, siendo por tanto el drama social y policíaco el género más recurrente en su obra literaria. Se dice que incluso muchos de los personajes que creó estaban basados en personas reales que había conocido en el curso de sus experiencias en la policía (Gordon, 1997, 13). Para conocer bien la obra literaria de 
Méténier, más concretamente su teatro, y para saber también cómo un funcionario aficionado a las letras acabó fundando una de las compañías más pintorescas de la historia del arte dramático, es necesario remontarse años atrás.

Diez años antes del fundar el Grand Guignol, Méténier conoció al empresario teatral André Antoine (1858-1943), un gran entendido de las artes escénicas y que apostaba por una puesta en escena naturalista, rechazando las expresiones grandilocuentes, amaneradas y retóricas del teatro del romanticismo, ya en el principio de su declive en aquellos años finiseculares. Más en consonancia con el pensamiento positivista, el teatro naturalista de Antoine sustituía la afectación por sencillez y se servía de tramas comunes y personajes cercanos para poner en escena piezas cuyos argumentos resultaban ciertamente familiares para el público urbano y burgués de las metrópolis europeas (Hand y Wilson, 2013, 5).

No obstante, a Antoine pronto se le quedaron pequeños los postulados del teatro naturalista más canónico. Tenía en mente, en su lugar, un tipo de naturalismo dramático extremo cuyos argumentos estuviesen poblados de pobres, prostitutas, delincuentes, alcohólicos y otros personajes que se moviesen en ambientes sórdidos y marginales; se recurriría igualmente a aquellas otras temáticas más comunes, pero también desasosegantes tales como los conflictos en el seno de la familia, el adulterio, el maltrato, etc. De esta manera, en parte y muy sutilmente, se rescataban algunos postulados del romanticismo, en especial el uso de las emociones intensas. A este nuevo género se le habría de llamar comédies rosses (teatro cruel, maligno). Fue el resultado, insistimos, de la querencia por mostrar sobre el escenario de forma más intensa determinados estados de arrebatamiento y pasión. Por ello, pese a que Antonie llevó a las tablas del Théâtre Libre a autores como Ibsen, Tolstói, Hauptmann, Strindberg, Becque o Zola (dramaturgos adscritos al naturalismo), su forma de entender el drama no encajaba del todo con ese repertorio. Dio cabida así a nuevos autores cuyas obras sí se adecuaban al estilo de las comédies rosses. Se llegarían a estrenar en el Théâtre Libre hasta ciento veinte obras nuevas de más de cincuenta autores distintos, la mayoría de ellos jóvenes (George Avery, Jean Jullien, Alfred Athis, Georges Courteline, Emile Fabre, Francois de Curel, y Brieux entre otros). 
La irrupción de este nuevo género o subgénero no se debió tan solo a la novedosa concepción de lo naturalista que tenía Antoine, sino también a la demanda del público cuyo gusto fue modelado, a su vez, por la novela gótica y folletinesca (surgida y consolidada a lo largo del siglo XIX) y por el éxito de la prensa amarilla, plagada de noticias sobre asesinatos y otros crímenes a cuál más mórbido. Estas noticias encandilaban al público francés (y más concretamente parisino) y no eran precisamente infrecuentes.

El 30 de mayo de 1887 se estrena en el Théâtre Libre la obra En Familie, escrita por Oscar Méténier. Contaba una historia centrada en los bajos fondos parisienses: el regente de un establecimiento donde se negocia con mercancía robada tiene una hija prostituta y un hijo ratero. Él mismo es alcohólico. Se reúnen todos para la cena y el hijo cuenta con detalle cómo ha sido la ejecución en la guillotina de su compañero de correrías. Es En Familie un ejemplo emblemático de comédie rosse, como también los fueron La Casserole (1889), la historia de una prostituta que delata a su amante, un delincuente que se venga acuchillándola, y Mademoiselle Fifi (1896), que nos cuenta cómo un oficial del ejército prusiano es igualmente acuchillado hasta la muerte por una prostituta francesa, ambas estrenadas también en el Théâtre Libre. Estas obras tenían dos rasgos llamativos: en cuanto a la forma, eran piezas de teatro breve, que apenas superaban la media hora de duración (muy común, por otro lado, del Théâtre Libre) y en cuanto al fondo, el naturalismo de sus argumentos era sustituido por un realismo crudo y truculento.

Méténier contó en una conferencia titulada «En Famille et la censure», dada en la Salle des Capucines de París el 19 de diciembre de 1890, todas las vicisitudes de su obra En Famille desde que fue escrita hasta que fue representada y todos los avatares burocráticos por los que pasó hasta que consiguió la oportuna aprobación de la censura. Estos avatares comprendieron las innumerables visitas a los despachos de los órganos censores y ministros del ramo. Como diría el mismo Méténier en aquella conferencia, «los ministros pasan, pero las oficinas permanecen», evidenciando así la poca fe en la capacidad de rectificación de los burócratas cuando una decisión administrativa ha sido ya tomada. Con tanto sentido del humor como ironía, Méténier describe su peregrinaje por las oficinas y dependencias de los organismos de la censura: «Y durante ocho días maravillosos, no hacía más que ir de Caifás a Pilatos»> (Méténier, 1891, 24). Otra de sus 
obras, La Cesserole, tuvo igualmente problemas con la censura, relatados en este caso en la conferencia, «Á Propos de La Casserole», pronunciada en el Théâtre Molière de Bruselas el 12 de marzo de 1891. Méténier reuniría ambas conferencias en un volumen publicado en 1891: Les Voyous au Théâtre.

Grande era la experiencia que tenía Méténier, por tanto, en tratar con los órganos encargados de la censura y grande era también su conocimiento acerca de los mecanismos que la hacen funcionar. No era menor la inmunidad de ánimo que llegó a desarrollar precisamente a fuerza de tanto tener que lidiar con las constantes cortapisas, condicionamientos, e incluso atropellos, de la actividad censora.

Este espíritu inquebrantable venía a su vez forjado en la larga experiencia que Méténier había desarrollado durante su etapa funcionarial. Los entresijos de la burocracia (y la predisposición a la arbitrariedad de los burócratas) no le eran ajenos. Había formado parte de ese mundo y sabía no solo identificarlos y evaluarlos, sino también, sortearlos. Buena fe de ello habría de dar en su siguiente proyecto empresarial en solitario. En efecto, cuando se separó de André Antoine en 1897, Méténier emprendió su propia aventura teatral: Le théâtre du Grand Guignol, objeto de nuestro estudio.

\section{La noche de la inauguración}

El 13 de abril de 1897 se inauguró el Grand Guignol. Tomaba el testigo Méténier de la forma de hacer teatro aprendida a la sombra de André Antoine, y no solo en cuanto a adoptar el naturalismo tremendista como estilo de la compañía (que acabaría derivando, con el paso de los años, en formas de terror delirante y grotesco), sino en cuanto al formato de las sesiones: todos los programas lo constituirían siempre obras de teatro breve que habrían de alternar la comedia y el drama perturbador. Esta alternancia entre comedia y drama (y aprovechamos para indicar que, pese a que el Grand Guignol siempre será conocido y reconocido como el teatro del espanto, no debe ser desdeñada esa importante parte de su repertorio compuesta por comedias, sainetes y vodeviles, algunos de gran calidad) estaba perfectamente calculada: el fuerte contraste generado por el cambio de género en un mismo programa provocaba un cierto efecto balsámico (una comedia alivia al público que acaba de asistir a un espectáculo de terror) y al 
mismo tiempo perturbador (una pieza de terror sobrecoge al público más intensamente si éste acaba de presenciar una comedia ligera). El programa que debía componer aquella primera sesión contenía las siguientes obras breves (Pierron, 1995, 1403):

Boniments de Mlle Guignol. A modo de prólogo y verdadero punto de partida de la compañía. Fue escrito por Hugues Delorme (seudónimo de Georges FrançoisThiébost).

- La Brême. Comedia dividida en dos escenas calificadas como mours populaires (costumbres populares) obra del fundador de la compañía, Oscar Méténier.

- $\quad$ Coup de fusil. Comedia de un acto de Georges Courteline, donde el tema a tratar era el de los abusos y sinrazones de las administraciones. El autor se convertiría con el tiempo en uno de los dramaturgos de referencia de la compañía y su temática más recurrente, en efecto, la de la crítica a la burocracia.

- Sans dot. Como la siguiente, un drama de Jean Lorrain, autor adscrito al simbolismo y otro fijo de la compañía en sus primeros años.

- $\quad$ Leurfrère.

- $\quad$ Monsieur Badin, comedia de un acto, de nuevo de Georges Courteline.

- $\quad$ Mademoiselle Fifi. La noche terminaba con este intensísimo drama de Oscar Méténier; verdadero clímax de la noche.

Pues bien, Oscar Méténier no obtuvo la pertinente visa o autorización para subir a escena este programa. Tres días más tarde, la prensa recogía la noticia de la frustrada inauguración de la compañía. El periódico Le XIX Siècle, en una crónica firmada por Paul Gegnon, decía en su primera página:

\section{En el Grand Guignol}

Más de lo mismo - La tiranía de la policía - El Gran Guignol prohibido al Sr. Oscar Méténier por la prefectura - La visa esencial

Como no tiene mucho que hacer en este momento, la prefectura de la policía [...] asigna a todos los oficiales de seguridad disponibles a los diversos cabarets del montículo [se 
refiere a Montmartre, situado en la falda de una colina], tomando notas [...] para dar a sus jefes una alta idea de su modestia y sus aptitudes literarias, señalando sin piedad coplas o escenas que no tienen la mente para comprender.

[...] Hablamos ahora del Grand Guignol, un verdadero teatro, que tiene en su programa los nombres de los señores Georges Courteline, Oscar Méténier y Jean Lorrain. [...]

Pero la prefectura de policía no hace distinción. ¿Alguna vez lo hace? [...] el prefecto de la policía acaba de prohibir la apertura de la sala, coquetamente decorada, del número 22 de la calle Chaptal [...]. (Gegnon, 1897, 1)

Le Journal de ese mismo día y bajo el título de «Le censure et Montmartre», da más detalles sobre las cortapisas dadas en la inauguración al Grand Guignol: hasta el martes de Pascua de aquel año (que habría de ser pocos días después al estreno de la compañía) se había dado una suerte de dispensa a los teatros y cabarets de Montmartre en cuanto al cumplimiento de las imposiciones censoras. Ningún otro local de lo que el cronista de Le Journal llama «la ladera de la colina sagrada» tuvo problema alguno. Pero el Grand Guignol no solo sí los tuvo, sino que fueron absurdos. Al parecer, la causa oficial de los impedimentos para la apertura fue el no haber superado los requisitos referidos a seguridad de la sala. Lo cierto es que el Grand Guignol no tuvo el permiso de los bomberos en cuanto a las normas de seguridad no porque la sala careciera de ellos, sino porque los bomberos no daban el visto bueno si no había previamente una autorización de la censura, que no existía. Con lo cual, aunque oficialmente el problema era de seguridad (mero subterfugio 'jesuita' en palabras del cronista de Le Journal), la causa real fue la simple y contundente aplicación de la censura. Además, los órganos censores no consideraban que el Grand Guignol fuese un nuevo negocio teatral, sino una continuación de la compañía que antes había funcionado en la misma sala: Le Théâtre-Salon, cuya actividad cesó cuando sus propios problemas con la censura no habían finalizado.

El cronista de Le Journal, fue mucho más combativo que el de Le XIX Siècle: no solo reprochó al resto de la prensa su silencio ante el atropello cometido, sino que lanza toda una proclama en favor de la libertad en el mundo artístico: 
[...] Era fácil prever que la pequeña guerra recientemente declarada a las nuevas formas escénicas y los teatros pequeños, dramáticos o líricos, que pululaban en la ladera de la colina sagrada pronto traería medidas ilógicas o puramente arbitrarias.

Siempre ha sido ilógico, pero ya se empieza a adivinar la arbitrariedad; quizás pronto se utilice como pretexto lo ocurrido en Montmartre para restringir, en cualquier otro lugar y para actos más interesantes desde cualquier punto de vista, una libertad hasta ahora era imperiosamente exigida en nombre del arte y conquistada, finalmente, después de mucho trabajo duro.

Pequeñas causas producen grandes efectos. La censura, reducida al ejercicio de un poder elegante, está resurgiendo en este momento en la pequeña familia de autores. Apetitos más grandes vendrán a él, esta primera digestión hecha [...]. (Anónimo, 1897, 2)

Varias son las cuestiones que merecen un comentario a la luz de estas reseñas de la prensa. En primer lugar, es muy llamativa la reiterada alusión a Montmartre.

El barrio de Montmartre fue, durante muchos años, una localidad independiente de París, situada extramuros de la ciudad. Como consecuencia de los planeamientos urbanos adoptados durante el siglo XIX, se derribaron las murallas y en el espacio libre se ocupó por amplios y elegantes bulevares. Montmartre se integró así en la capital, pero siguió manteniendo un estatus administrativo propio. Entre los «privilegios» del que ya era un barrio de París estaba el de poder dispensar en sus locales alcohol sin límite alguno. De este modo, mientras en la ciudad propiamente dicha los locales de ocio (y sus clientes) eran más comedidos, en Montmartre los innumerables tabernas, cabarets, teatros y salones nocturnos que fueron surgieron a lo largo del siglo XIX, no solo eran más licenciosos y libertinos, sino que contribuyeron a consolidar en el barrio un estilo de vida bohemio y marginal (años más tarde, sin ir más lejos, en Montmartre se instalaría el movimiento revolucionario conocido como la Comuna de París). Al mismo tiempo que vividores, prostitutas y delincuentes encontraban un hueco en Montmartre (que además era limítrofe con el barrio rojo de Pigalle), también lo hacían artistas de pocos recursos. Es así como, pese a ser un lugar, en cierta manera, a evitar, también fue el hogar de un estilo de vida abierto, sin prejuicios y, paradójicamente, hospitalario hacia cierto modo de vida alternativo. 
A la luz de esta circunstancia es como se debe entender las referencias expresas o metafóricas, tanto del cronista de Le XIX Siècle como el de Le Journal, a Montmartre. Existía una especial sensibilización ante los atropellos de la censura que pudieran producirse en el barrio más que los que eventualmente pudieran tener lugar en otros locales de París y ello porque se daba por sentado que los movimientos artísticos e intelectuales que se desarrollaban en la colina eran merecedores de una especial tolerancia. Ejercer la censura en Montmartre se entendía como un ejercicio de la misma que iba más allá de cualquier comedimiento o prudencia.

Es por ello, insistimos, por lo que la prensa se puso manifiesta e inequívocamente del lado del Grand Guignol y su incipiente actividad teatral. Ponerse de parte de la pequeña sala recién abierta era alinearse igualmente con la modernidad, la vanguardia, la libertad y la tolerancia.

Y todo ello pese a que, en rigor, el Grand Guignol no era un local montmatreño. Lo cierto es que el Grand Guignol estaba situado administrativamente en Pigalle (al otro lado del bulevar de Clichy, que lo separa de Montmartre), pero siendo su actividad artística (en su caso, teatral) hasta cierto punto provocadora, y desde luego poco convencional, estaba clara su alineación con los vecinos de la colina.

Conocemos ya, pues, cuáles fueron las cortapisas que concurrieron en la inauguración del Grand Guignol y el porqué de las alusiones de los cronistas al barrio de Montmartre. Veamos ahora cómo Méténier sorteó la situación. La crónica de Le XIX Siècle nos sigue diciendo:

[...] Anoche fuimos a Grand Guignol. En la puerta de entrada, leemos el siguiente cartel: Representación privada. Solo admisión por invitación. N.B. Solo se cobrarán las cuotas del guardarropa.

Con casi ningún control entramos y encontramos al señor Oscar Méténier, que nos entrega una nota con la mención Invitación. Por lo tanto, la entrada es gratuita y gracias a este proceso el Grand Guignol no ha cerrado sus puertas, respetando la prohibición de cierre al público.

Así nos informa el autor de Mademoiselle Fifi: «En la jefatura de policía, donde fui esta tarde, me dijeron formalmente que no tendríamos permiso para abrir porque no 
estábamos en buena posición con la censura [...] me opuse a que se nos denegase lo se había otorgado a todos los demás cabarets. Obtén la visa, me dijeron. Obviamente fue una broma ya que les toma por lo menos quince días leer un acto, por lo que pusieron ante mí un obstáculo insuperable. Le pedí al prefecto un indulto. Respondió que tenía la intención de no otorgarlo tan fácilmente, como en el pasado sí hizo con la apertura de 3 establecimientos similares a los nuestros. [...] Él se opuso categóricamente. El espectáculo no se representará [...] Para no cerrar, invitamos a todos nuestros amigos. La comisión de teatro que vino ayer comprobó la sala y nuestros arreglos y descubrió que todo estaba en perfectas condiciones. Estamos decididos a representar de todos modos. Invitando a todos, por supuesto, estamos sufriendo grandes pérdidas. Sin embargo, no he perdido la esperanza y todavía espero poder superar estas dificultades».

Cuando dejamos al Sr. Oscar Méténier, nos atrapó su teatro con una risa tremenda. Disfrutando con Monsieur Badin, de Georges Courteline. Esta pieza simboliza bellamente esto de que en las administraciones hay pereza en algunos y cretinismo en otros. (Anónimo, 1897, 2)

Nos dice la crónica que, para eludir la prohibición de la apertura al público, al pícaro Méténier se le ocurrió que la función del día de la inauguración fuese privada previa invitación, para a continuación repartir invitaciones a todo el que aquella noche se acercase por el teatro que, por cierto, se llenó. Fue una jugada maestra. Al ser una actividad privada, las autoridades no tenían potestad alguna y el espectáculo no podía ser censurado. Méténier conocía perfectamente las reglas del juego al que estaba jugando; su experiencia durante tantos años siendo funcionario de la policía (conociendo a la perfección todos los entresijos de la burocracia), por un lado, y los episodios ya vividos cuando se censuraron sus obras En Famille y La Casserole en el Théâtre Libre, por otro, le habían instruido sobre cómo actuar en un caso como aquel. Méténier no actuó ni ilegal ni clandestinamente, ni falta que le hacía. Su proceder fue perfectamente legal y además consiguió, no solo llenar el teatro, sino que además el evento tuviese una repercusión en prensa más que sobresaliente. El único inconveniente fue que la recaudación en taquilla más que baja, fue inexistente. Pero fue un contratiempo más que salvable para el emprendedor y arrojado Méténier.

Con todo lo dicho, no obstante, hay un aspecto no tratado por las crónicas periodísticas referidas y que es de gran importancia: exactamente, ¿qué vieron las autoridades censoras en aquel primer programa del Grand Guignol para que el mismo 
fuese censurado? La pieza principal de entre las que componían el programa era aquella que lo cerraba: Mademoiselle Fifi. Esta obra contaba la historia de una prostituta francesa llamada Rachel que acude a un caserón ocupado por un destacamento del invasor ejército prusiano, en el que se ha instalado uno de sus cuarteles. Los oficiales enemigos, ociosos, organizan una fiesta depravada a la que acuden mujeres locales, entre ellas la protagonista Rachel. Uno de esos oficiales es un petulante, amanerado y odioso prusiano al que sus compañeros llaman despectivamente Mademoiselle Fifi. Afectado por el alcohol y por el desenfreno de la orgía, empieza a lanzar ofensas crueles hacia Francia y los franceses. Aunque en un primer momento Rachel no se ve afectada por tales ofensas, llega un momento en que no aguanta más y apuñala con ensañamiento y hasta la muerte a Mademoiselle Fifi. Huye y se convierte en una heroína local.

Esta obra ya había sido representada el año anterior en el Théâtre Libre. No se entiende, por tanto, por qué la censura impidió la representación de una obra que en aquel otro escenario se ejecutó sin cortapisas. Probablemente la contradicción se resuelva dando por el hecho la arbitrariedad y el capricho con que actuaban los órganos censores. Es posible también que esos mismos órganos se mostrasen tolerantes con una sala de fama ya consolidada en París (el Théâtre Libre) pero que no estuviesen dispuestos a que un negocio nuevo (el Grand Guignol) abundase en esa misma línea de espectáculos, razón por la cual se impusiese una llamada al orden desde el mismo comienzo.

Por un motivo o por otro, es cierto que Mademoiselle Fifi era una obra polémica. Adaptaba a las tablas el relato de Guy de Maupassant del mismo título publicado el 23 de marzo de 1882 en la revista Gil Blas; un conte cruel tan propio de la obra del autor, con un escabroso argumento y un muy sangriento final. Maupassant, por cierto, era uno de esos personajes típicos del barrio de Montmartre, alcohólico y mujeriego, que vivió sus últimos años de vida en un sanatorio mental aquejado por los delirios que le provocó su adicción a la bebida. Todo un personaje granguiñolesco. Al incluir en el primer programa del Grand Guignol una obra adaptada de un relato de Maupassant, Méténier firmaba una declaración de intenciones: el Grand Guignol sería para el panorama teatral lo que la obra de Maupassant lo fue para el literario. No es solo que la maestría de Maupassant para mostrar personajes arrebatados y situaciones grotescas fuera digna de ser imitada en las tablas (Maupassant acabaría siendo, con los años, el 
autor más adaptado en el Grand Guignol; más incluso que Edgar Allan Poe), sino que la controversia, la polémica y la agitación que tan apropiadamente caracterizaba la obra del autor, también habría de acompañar para siempre la andadura de aquel nuevo y pequeño teatro de Pigalle.

\section{El indicente dichotomie}

En los años 10 del siglo Xx el Grand Guignol aún era joven, pero ya se había consolidado su merecida fama de ser el teatro de lo perturbador y horripilante (Rivière y Wittkop, 1979, 17). Eran de tan calibre los actos sanguinolentos que se representaban sobre el escenario que muchos espectadores sufrían mareos y vómitos. Se anunciaba en su publicidad que un médico siempre estaría en la sala para atender los desmayos que se produjesen. Se podría pensar que esto no era más que una estratagema publicitaria y que aquel individuo quizás ni siquiera fuese médico. Pero no. Sabemos que sí era un médico colegiado precisamente gracias a lo ocurrido en 1911. [Fig. 2]

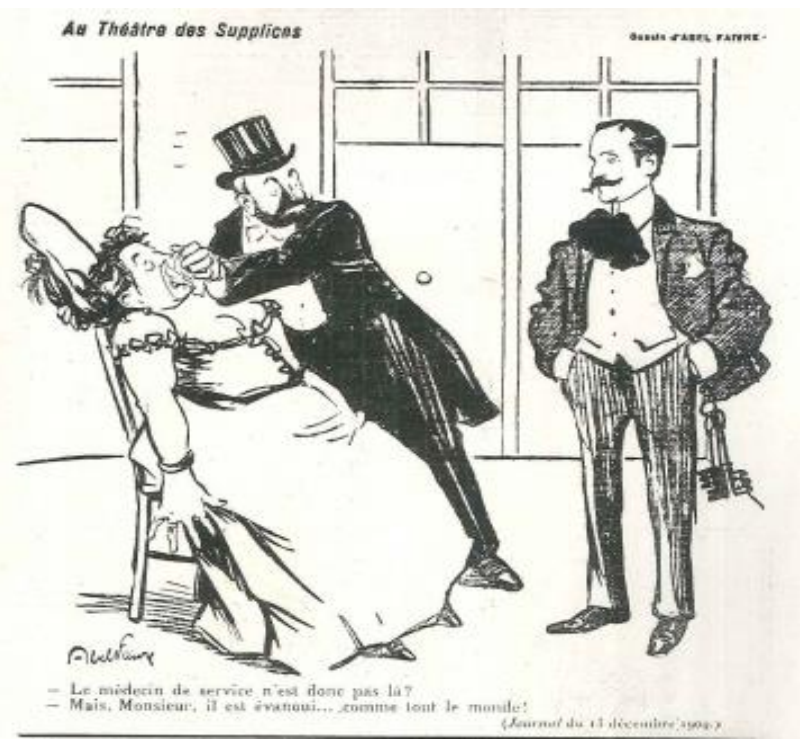

2. Abel Faivre. Viñeta.

- Y el médico de servicio, ¿dónde está?

- Pero señor... Se ha desmayado, como todo el mundo.

Le Journal, 3 de diciembre de 1904. Biblioteca Nacional de Francia.

Dichotomie (André Mouëzy-Éon, drama en dos actos, 1911) no era una obra de terror; era un drama intenso que nos contaba la historia de una mujer enferma que, aun 
no necesitando de ser intervenida quirúrgicamente, su médico la manda operar para así cobrar a medias los altos honorarios que va a facturar el cirujano. Durante la anestesia, la mujer muere. El escándalo que generó esta pieza fue monumental. Pese a los esfuerzos de Mouëzy-Éon, el autor, en destacar que la obra narraba la acción excepcional de una oveja negra y que, en todo caso, debía interpretarse a la luz del juego de la exageración propio del Grand Guignol, no se pudo evitar la polémica. La clase médica se manifestó contra la obra y en una conferencia dada por el doctor Doyen en el Théâtre Fémina titulada Y a-t-il encore aujourd'hui des médecins de Molière? («¿Aún hay médicos como el de Molière? »), se exigió la dimisión del interventor Delbaise por haber concedido la autorización para la representación de la obra (Mouëzy-Eon, 1963, 50). Como resultado de estos incidentes, al Grand Guignol se le privó de la presencia diaria del médico de guardia durante varios meses. Gracias, pues, a este episodio sabemos con certeza que aquel médico de guardia que habría de atender los desmayos del público era, ciertamente, real (Mouëzy-Eon, 1963, 52).

A André Mouëzy-Éon le afectó la polémica y no volvería a escribir obras de este tipo (se centraría en el género de la comedia, que era el que con más asiduidad practicaba), aunque, una vez más, el Grand Guignol se vio favorecido publicitariamente de la controversia y la sala disfrutó de llenos constantes. Además, Dichotomie fue un gran éxito de crítica.

Sin duda lo ocurrido con Dichotomie, fue un incidente trascendente en la historia del Grand Guignol, pero más interés, a los efectos de este artículo, tiene lo ocurrido unos años antes. Le chirurgien de Service (Johannès Gravier y A. Lebert, drama en un acto, 1905) era, de nuevo, un drama intenso [Fig. 3]. Nos contaba esta pieza la historia de una mujer con problemas en su embarazo, concretamente una grave hemorragia interna, que acude a las urgencias de un hospital donde solo hay residentes que no está autorizados a practicar intervenciones quirúrgicas. Se produce una discusión entre éstos en cuanto a si es oportuno intervenir a la mujer sin el permiso del jefe de sección y en contra del reglamento. Cuando por fin se presenta el cirujano capacitado, la mujer acaba de morir. Esta obra también causó una gran polémica (aunque mucho menor que la generada por Dichotomie) y su repercusión fue tal que la normativa de las urgencias de los hospitales de París se modificó para evitar desgracias como la sufrida por la protagonista de la obra. Una vez más la ley protagoniza un episodio en la historia del 
Grand Guignol, solo que esta vez no hablamos de la aplicación o elusión de una norma censora, sino de cómo el descaro de una pequeña y grotesca compañía teatral pudo ser capaz de alterar la normativa de atención sanitaria de una gran ciudad.

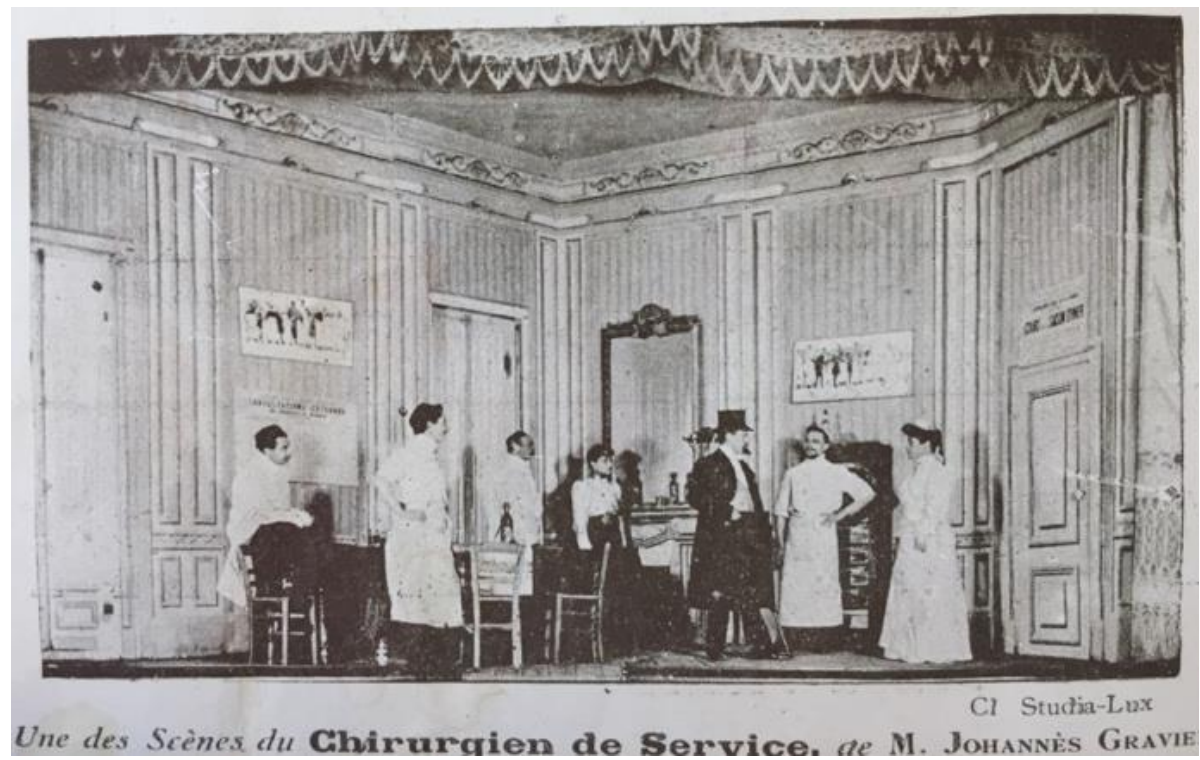

3. Escena de Le chirurgien de Service. Programa de la temporada 1911. Instituto Nacional de Historia del Arte. París.

\section{Georges Courteline}

Referimos en su momento que en el Grand Guignol fueron representadas obras de terror, pero también dramas intensos e incluso comedias. También hemos referido que en la noche de la inauguración se representaron dos comedias de Georges Courteline, autor que acabaría siendo uno de los más asiduos en el repertorio de la compañía.

Además de las ya referidas, Coup de fusil y Monsieur Badin, podemos citar, a título de ejemplo, otras obras de Courteline como son Hortense, ;couche-toi! (un acto, 1897) y La Lettre chargée (un acto, 1902). La primera nos cuenta cómo el dueño de un inmueble debe vivir a la intemperie por no poder echar al inquilino, que se conoce todas las triquiñuelas legales para permanecer en la vivienda. Aún incluso cuando es desalojado, el nuevo ocupante, igualmente pícaro, continúa con la misma actitud, y el desgraciado propietario debe seguir viviendo bajo raso. La segunda, narra la historia de un empleado de correos que se niega a entregar una carta a su destinatario por no poder acreditar documentalmente su identidad, pese a que son viejos amigos. El funcionario 
de correos, celoso guardador de la ley, pero con un concepto muy peculiar de la misma, sugiere a su amigo que busque a un tercero que falsifique su firma.

Observamos claramente que la temática en estas comedias de Courteline es la de la ridiculización de los sistemas normativos y las consecuencias absurdas a que puede llevar la aplicación rigurosa, pero irreflexiva y laberíntica, de la ley. Exfuncionario (como Méténier) y exmilitar, Courteline sabía cómo provocar en el público un sentimiento de empatía hacia el desgraciado protagonista atrapado por los enredos legales y reglamentarios.

El Grand Guignol convirtió así su propio padecimiento ante los mecanismos legales de la censura en fuente de inspiración para sus comedias más acertadas, dándole la vuelta a la situación que le tocó vivir, riéndose de aquello que más daño podía infligirle y haciendo de dicho padecimiento un elemento inspirador propicio para la creación teatral. Pero, sobre todo, supo hacer partícipe a su público de su desprecio ante los atropellos legales parodiando hasta el paroxismo la ridiculez del sistema legal.

\section{Y, por fin, el terror}

Si las comedias de Georges Courteline explotaban como elemento temático el comportamiento absurdo de la burocracia y la aplicación de ley, la más reconocida parte de su repertorio, aquella que englobaba las obras de terror más perturbador, hizo lo propio. Son innumerables las piezas de terror donde la aplicación ciega de la norma es el detonante de la tragedia. Examinamos algunas de ellas, una vez más a título de mero ejemplo.

Le Viol (Jean d'Astorg, dos actos, 1918), es la historia de un asesino que, por miedo a ser condenado a pena de muerte y conocedor de los resquicios legales, finge estar loco. Se salva, en efecto de la pena capital, pero es llevado a un manicomio y recluido en una celda donde un loco le clava un estilete en los ojos.

Un crime dans une maison de fous (André de Lorde y Alfred Binet, dos actos, 1925) nos muestra a la inocente Louise, una desafortunada joven que por error ha sido internada, de nuevo, en un manicomio. Pese a convencer al facultativo responsable de su cordura, por culpa de un impedimento legal no puede salir de la institución de 
inmediato. La noche previa a su alta, es asesinada por otras internas que le arrancan los ojos (se observará que tanto el manicomio como institución legal, desaprensiva, amenazante y peligrosa es un entorno recurrente en las obras del Grand Guignol, así como que el hecho de que sacarles los ojos a las víctimas era una de las maldades más habituales de los dramaturgos de la compañía).

L'Horrible Passion (André de Lorde y Henri Bauche, tres actos, 1934) cuenta cómo una niñera perturbada estrangula a los niños que tiene a su cuidado. A consecuencia de un resquicio legal, concretamente un dictamen forense especialmente benévolo, queda absuelta de toda pena cuando es juzgada. El médico forense firmante del dictamen es amigo de un matrimonio padres de un niño pequeño. La casualidad quiere que la asesina acabe trabajando para la pareja y, fatalmente, el pequeño muere asesinado a manos de la niñera.

En estas obras apreciamos una vez más un feroz ataque a las instituciones legales y a su forma impersonal, unilateral y arbitraria de funcionar, solo que, en lugar de hacerlo por vía de la risa, se hace por la del espanto. En ambos casos el resultado es el mismo: se hace pública, se evidencia, a efectos de escarnio, una situación reprochable que, sin duda, a los espectadores, ciudadanos sometidos al imperio de la ley, les resulta familiar.

\section{Conclusiones}

Nos preguntamos si la tendencia seguida por el Grand Guignol, a la hora de configurar las temáticas más habituales de su repertorio, hubiese sido igual caso de no haber sufrido constantemente las arbitrariedades de la censura y de no haber sido protagonista en polémicas generadas por su actividad dramática. Obviamente la respuesta es no.

El teatro del Grand Guignol fue hijo de su tiempo. Una abrumadoramente alta proporción de las obras que componen en su repertorio fueron obras originales, escritas directamente para la compañía. Sus autores no vivían en burbujas ni en torres de cristal. Eran personas que disfrutaban, pero también padecían, las condiciones inherentes al hecho de ser ciudadano de una metrópolis en un país importante. El Grand Guignol era además una compañía modesta que para sobrevivir debía darle al público, noche tras noche, aquello que asegurase una buena recaudación en taquilla. El repertorio, pues, del 
Grand Guignol fue configurándose a medida que la compañía crecía y lo hacía adaptándose al entorno y a las circunstancias. La actualidad se veía plasmada en sus obras y el estar sometido a las imposiciones de las autoridades formaba parte de esa actualidad. El Grand Guignol puso un espejo ante el contexto sociopolítico y cultural en el que nació y se desarrolló y mostró la imagen reflejada a su público, sin duda el mejor y más comprometido aliado de la compañía en su andadura.

El pequeño teatro de Pigalle sufrió ciertamente el embate de los órganos censores y los grupos de presión, pero, lejos de amilanarse, usó esa agresión a su favor e hizo de ella un campo fértil de creatividad. El público, insistimos, respondió al ver que las temáticas recurrentes de la compañía reflejaban sus propias inquietudes, aun cuando lo que se viese sobre el escenario fuera una fabulación.

Con el paso de los años, no obstante, las exigencias de la censura fueron debilitándose. Tras la Segunda Guerra Mundial, el Grand Guignol entró en una etapa de decadencia lenta pero inexorable que lo abocó al cierre en 1962. Durante sus últimos años, las obras representadas por la compañía sobrepasaron la fase de terror perturbador para adentrase groseramente en el más descarado delirio. Los desnudos y los momentos explícitamente sexuales, igualmente, fueron muy habituales sobre el escenario. El pequeño teatro del barrio de Pigalle se transformó en un reclamo para turistas que buscaban emociones fuertes más que calidad dramática. Lejos quedaba también el espíritu contestatario y descarado de la compañía fraguado con constancia a fuerza de soportar los embates de la burocracia censora. El estado de relajación y laxitud en cuanto al control de los contenidos de las obras representadas, paradójicamente, fue consumiendo la creatividad de la compañía y amilanó su insolencia y frescura.

Le théâtre du Grand Guignol du Paris pasará a la historia de las artes escénicas del siglo XX, en todo caso, como uno de sus episodios más fascinantes. Su trayectoria nos recuerda cómo la creatividad no solo florece aún en los entornos más hostiles, sino que esos mismos entornos pueden ser propicios en cuanto a la inspiración se refiere. Pero, asimismo, el Grand Guignol nos recuerda que toda forma de expresión artística, como lo es el arte dramático, camina de la mano del tiempo que le toca vivir y que su desarrollo y configuración sirven de testimonio de ese momento. Por todo ello, la historia del Grand Guignol de París es la historia de un compromiso con el arte, el 
ingenio y la excelencia y un ejemplo del afán de superación, determinación y constancia para toda actividad humana nacida de la imaginación.

\section{Referencias bibliográficas}

Gordon, Mel. (1997). The Grand Guignol. Theatre of fear and terror. New York, EE.UU.: Da Capo.

Hand, Richard J., y Wilson, Michael.

- (2007) London's Grand Guignol and the theatre of horror. Exeter, Reino Unido: University of Exeter Press.

- (2013). Grand-Guignol. The French theatre of horror. Exeter, Reino Unido: University of Exeter Press.

Hunter, Jack. (2011). Chapel of gore and psychosis; The Grand Guignol Theatre. Hove, EE.UU.: Creation Books.

Méténier, Oscar. (1891). Les Voyous au Théâtre. Bruselas: Henry Kistemaeckers.

Mouëzy-Eon, André. (1963). Les adieux de la troupe. París: La table ronde.

Pierron, Agnès.

- (1995). Le Grand guignol: Le théâtre des peurs de la Belle Époque. París, Francia: Robert Laffont, S.A.

- (2002). Les nuits blanches du Grand-Guignol. París, Francia: Seuil

Rivière, François y Wittkop, Gabrielle. (1979). Grand Guignol. París, Francia: Henri Veyrier.

Thalasso, Adolphe (1909). Le Théâtre Libre. París : Mercure de France.

\section{Artículos}

Anónimo. (1897) Le censure et Montmartre. Le Journal, 16 de abril 1897, 2.

Gegnon, Paul. (1897) Au Grand Guignol. Le XIX Siècle, 16 de abril 1897, 1. 